\title{
A POSSIBLE CASE OF AFFINITY IN TOMATOES
}

\author{
MARGARET E. WALLACE \\ Department of Genetics, University of Cambridge
}

Received 1 7.vii.59

\section{INTRODUCTION}

EvIDENCE for the existence of the new genetic phenomenon, affinity, is now fairly extensive (Michie, I955a, $b$; Wallace, I958a, $b$, I960 $b$; Chatterley, I958; Parsons, I959). This has so far been entirely confined to the house mouse. Its occurrence in other species, particularly in plants rather than in animals, would be of considerable genetic and evolutionary interest.

Sir Joseph Hutchinson has drawn my attention to the existence of what appear to be significant quasi-linkages in cotton and in the tomato. It seems worth considering these, therefore, in the light of an affinity hypothesis. An analysis of the tomato data (Sawant, I958) is the subject of this paper, the cotton data, which are rather more extensive, being treated elsewhere (Wallace, I $660 a$ ).

\section{THEORETICAL CONSIDERATIONS}

First, a brief account of the place of quasi-linkage in affinity is relevant. The theory of affinity supposes that more than one kind of centromere is possible and that two (or more) may be present in the $F_{1}$ of crosses between distantly related stocks, varieties or species. When this is the case, the centromeres of like kind, that is, supposedly from the same ancestral origin, tend to travel to the same pole at the first division of meiosis. Genetic markers linked to the centromeres then tend to be associated, that is to show quasi-linkage. The recombination values have so far been of the order of 40 to 45 per cent. Work with laboratory stocks from several countries has shown (Wallace, r $958 a$, etc.) that recombination values in excess of 50 per cent. (or reversals) are possible and have been obtained; they result from the attraction of like centromeres which have come from different parents, i.e. from divergent heterocentric heterozygotes.

The recombination values obtained from reversals have been in the order of 55 to 60 per cent.; as such they constitute a feature strikingly different from linkage.*

It is clear, then, that the situation most susceptible of an affinity interpretation is one where markers, which behave as if independent within the stock or species, show quasi-linkage when segregating in a

* Barring chromatid interference; this may usually be expected to produce values not in excess of $5^{6}$ per cent. (Wright, I947, and Fisher, Lyon and Owen, 1947). 
heterozygote from a cross between two stocks or species; this is particularly so when the quasi-linkage value exceeds 50 per cent.

Sawant's data exhibit precisely this situation.

\section{THE DATA}

During a study of the phylogenetic relations of a stock of $L$. esculentum Mill. and two forms of $L$. hirsutum Humb. Bonpl., Sawant obtained a $c /++$ and sp $m s_{2} /++$ hybrids, which were selfed and backcrossed to the multiple recessive. The mutants were obtained in each case from the esculentum parent, $a$ and $c$ from the San Marzano variety and $s p$ and $m s_{2}$ from the Pearson variety. There were two types of hybrid of each coupling heterozygote, one having its ++ contribution from

TABLE I

Quasi-linkage of independent markers in hybrids of

L. esculentum $\times$ L. hirsutum

\begin{tabular}{|c|c|c|c|c|c|c|c|c|}
\hline \multirow{4}{*}{$\begin{array}{l}\text { Mating type * } \\
\text { I. a (V) and c } \\
\text { (IV) } \\
\text { B.c. . } \\
\text { I.c. } \\
\text { B.c. . }\end{array}$} & \multirow{4}{*}{\begin{tabular}{|l|}
$\begin{array}{c}\text { Origin of } \\
\text { hirsutum } \\
\text { chromosomes }\end{array}$ \\
\\
Baños \\
Baños \\
Chillon
\end{tabular}} & \multicolumn{4}{|c|}{ Phenotypes of progeny } & \multirow{2}{*}{$\begin{array}{l}\text { Contingency } \\
\chi^{2} \text { for I d.f. }\end{array}$} & \multirow[t]{2}{*}{$p$} & \multirow{2}{*}{$\begin{array}{l}\text { Recombina- } \\
\text { tion value } \\
\text { per cent. }\end{array}$} \\
\hline & & ++ & $a+$ & $+c$ & $a c$ & & & \\
\hline & & $\begin{array}{l}171 \\
304\end{array}$ & 157 & I 36 & $\begin{array}{r}186 \\
37\end{array}$ & $\begin{array}{l}5.99 \\
0.15\end{array}$ & $0 \cdot 02-0 \cdot 01$ & $45 \cdot I$ \\
\hline & & $\begin{array}{l}304 \\
165\end{array}$ & $\begin{array}{l}15^{8} \\
\end{array}$ & $\begin{array}{l}114 \\
117\end{array}$ & $\begin{array}{r}37 \\
172\end{array}$ & $\begin{array}{l}0.15 \\
6 \cdot 47\end{array}$ & $\begin{array}{l}0.7-0.5 \\
0.02-0.01\end{array}$ & $\begin{array}{l}51 \cdot 5 \\
44 \cdot 9\end{array}$ \\
\hline II. $s p \quad \underset{m s_{2}}{(\mathrm{IV})}$ (I) & & $+t$ & $s p+$ & $+m s_{2}$ & $s p m s_{2}$ & & & \\
\hline B.c. . & Baños & 45 & 97 & $4^{\circ}$ & 47 & $4 \cdot 12$ & $0 \cdot 05^{-0} \cdot 02$ & $57 \cdot 5$ \\
\hline B.c. . & Chillon & $\begin{array}{r}07 \\
14^{\circ}\end{array}$ & $\begin{array}{r}444 \\
182\end{array}$ & $\begin{array}{r}24 \\
127\end{array}$ & $\begin{array}{r}9 \\
14^{2}\end{array}$ & $\begin{array}{l}1 \cdot 18 \\
0.68\end{array}$ & $\begin{array}{l}0.3-0 \cdot 2 \\
0.5-0.3\end{array}$ & $\begin{array}{l}58 \cdot 2 \\
51 \cdot 9\end{array}$ \\
\hline
\end{tabular}

* All data are coupling. B.c. = Backcross, I.c. $=$ Intercross.

In I : $\chi_{1}^{2}$ testing difference in recombination between Baños I.c. and Baños B.c. is $2 \cdot 9 \mathrm{I}$, $p=0 \cdot \mathrm{I}-0 \cdot 05$.

In II : $\chi_{1}^{2}$ testing difference in recombination between combined Baños and Chillon is $2 \cdot 45, p=0 \cdot 2-0 \cdot 1$.

the Baños stock of hirsutum and one having it from the Chillon stock of hirsutum.

Genes $a, c, s p$ and $m s_{2}$ are anthocyaninless, potato leaf, self-pruning and male-sterile respectively. Sawant observes that "Genes $a$ and $c$ are definitely known to be located on different chromosomes (Butler, 1952)". Rick and Butler (1956) place them in linkage groups V and IV respectively, with $s p$ and $m s_{2}$ in IV and I respectively. I and $\mathrm{V}$ are long, well-marked groups, and $s p$ is centrally placed in IV, so that independence between $a$ and $c$ and between $s p$ and $m s_{2}$ seems pretty certain.

The quasi-linkage data are summarised in table $\mathrm{I}$.

Sawant states that the assortment of $a$ with $c$ and of $s p$ with $m s_{2}$ " is not normal", and that for the latter two loci, his observations 
" contradict the now classical hypothesis that recombination classes in species crosses tend to be deficient and parental classes excessive". His analysis, however, while showing that the segregations show an overall deviation from expectation, is clearly not intended to discriminate critically between disturbances due to single-factor deviations (which occur in some parts of the data) and those due to the sort of non-independence usually ascribed to linkage and now familiar in mice as quasi-linkage. A new analysis is therefore presented in the table.

\section{THE ANALYSIS}

Four bodies of backcross data have been pooled, after a test of homogeneity, to give the $a c /++$ Baños backcross progeny figures, and four also to give the Baños intercross ones. The contingency $\chi^{2}$ (with Yates' correction) has been used throughout as this tests association whether or no there are single-factor deficiencies. In data where the single-factor ratios are insignificantly disturbed, the addition method of estimating the recombination value has been used, and where they are both significantly disturbed, the product method; in the intercross data, Fisher's scoring method has been used. The $\chi^{2}$ tests used in the last column are based on variances which take into account possible disturbances due to single-factor anomalies.

This analysis shows that for the $a$ and $c$ loci there is significant association in both the Baños and Chillon hybrids. Since the data are all in one phase (coupling) there is no way of knowing whether this is quasi-linkage or interaction (in the statistical sense) in terms of preferential fertilisation, preferential pollen abortion, or zygotic inviability. Interaction of this sort, however, seems unlikely, since it has not been reported in the tomato and indeed is unusual in any species. Pollen abortion in hybrids is common but Sawant has shown that it does not explain the anomalies of any part of his data.

The paper includes data for the linked genes $W o$ and $d$ (linkage group I), where the most likely explanation of the significant deficiency of recombinants in the esculentum $\times$ Chillon hybrid is shown to be a reduction in chiasma frequency. This is interesting: Sawant's cytological work shows that such a reduction occurs in chromosomes other than that corresponding to linkage group I. This being so, a tightening of linkage from marker to centromere is to be expected, and this, in turn, given centromeric attraction, must increase the overall degree of quasi-linkage of the markers. Sawant's cytological work, then, gives a mechanism whereby the effect of affinity, if operating, is expected to be enhanced. It is interesting to note that in cotton a tightening of linkage after interspecific crossing is commonly found, and there is now suggestive evidence that quasi-linkage also occurs after interspecific crossing.

The idea of interaction becomes even less plausible on consideration of the $s p-m s_{2}$ segregations. For one might reasonably suppose that interaction of any kind resulting from interspecific crossing would 
always tend to preserve the (presumably adaptive) parental phenotypes. For the $s p$ and $m s_{2}$ loci, however, as Sawant points out, it is the parental phenotypes which are deficient. In terms of linkage, the recombination value significantly exceeds 50 per cent., at least in the Baños hybrids, and thus the data exhibit this very distinctive feature of affinity. The homogeneity of each of the four bodies of data which contribute to the Baños $a-c$ segregations is also encouraging. In short, both two-point segregations support the affinity hypothesis, and one shows a reversal, a feature peculiar to it.

\section{DISCUSSION}

While it is hardly to be expected that data from experiments not designed to demonstrate affinity can be conclusively convincing, it is worth considering what its acceptance here implies for the centromeric constitutions of the stocks involved.

For the chromosomes corresponding to groups $\mathrm{V}$ and IV the Baños and Chillon hybrids may be conventionally written as:

$$
\begin{array}{ccl}
\mathrm{V} & \mathrm{IV} & \begin{array}{l}
\text { linkage groups } \\
+a
\end{array} \\
\frac{+a}{a \beta} & \begin{array}{l}
\text { hirsutum chromosomes (Baños and Chillon) } \\
\text { esculentum } \text { chromosomes (San Marzano) }
\end{array}
\end{array}
$$

where $\beta$ are the esculentum centromeres, and $\alpha$ the hirsutum. This notation is not intended to imply that the Baños centromeres are the same as those of the Ghillon, for the data do not reveal this, merely that in both hybrids a Baños centromere tends to choose another Baños one as companion in travelling to the pole, and similarly for the Ghillon one. If the other ten chromosomes are also heterocentric, and if attraction between any two similar centromeres is enhanced by attraction for similar ones in other chromosomes (Wallace, r958a, p. 2 I9), then the quasi-linkage of 45 per cent. is a product of this cumulative attraction. If the data had included centromere markers for other chromosomes, it might have been informative on this point: as it stands, one may merely conclude that for two, possibly more, chromosomes the San Marzano esculentum centromeres differ from those of both stocks of hirsutum.

For the IV and I chromosomes, the Baños hybrid is a divergent heterocentric and may be written

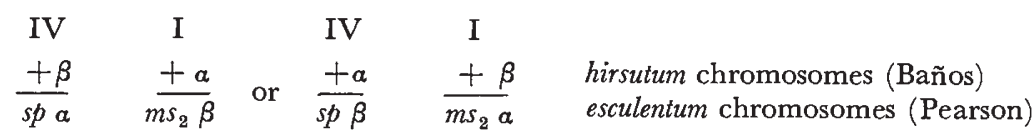

An alternative notation is given because these data alone do not reveal whether it is the group IV centromeres or the group I ones which have been interchanged. The important point is that there has been an interchange, for the centromeres which attract ( $\alpha$ to $\alpha$ and $\beta$ to $\beta$ ) come from different parents. Again, there may be a cumulative effect from heterocentricity of other chromosomes, and these may 
also include some interchanges, but the data do not reveal this; one may merely conclude that for these two chromosomes the esculentum and Baños centromeres differ and that an interchange of centromeres for at least one chromosome has taken place.*

Since $c$ and $s p$ are both in group IV, the next logical step is to write the Baños and esculentum chromosomes as follows:

$$
\begin{array}{cccl}
\mathrm{V} & \mathrm{IV} & \mathrm{I} & \\
\frac{+a}{a \beta} & \frac{++\alpha}{c s p \beta} & \frac{+\beta}{m s_{2} \alpha} & \begin{array}{l}
\text { hirsutum chromosomes (Baños) } \\
\text { esculentum chromosomes (San Marzano \& Pearson) }
\end{array}
\end{array}
$$

That is, assuming only two types of centromere, one of the alternative notations above is impossible and one must conclude that it is the group I centromeres which have been interchanged. This interpretation may well be correct, but there is a difficulty which must be mentioned. The esculentum parents used in the $a-c$ crosses were from a different stock (San Marzano) from those used in the $s p-m s_{2}$ crosses (Pearson), so that differing centrotypes are possible. However, though the two stocks may have been separated for more than Ioo years, their appearance is closely similar, apart from the mutants, and the breeding relationship between them is as good as within either of them (Sawant, private communication). The assumption of the same centrotype is thus reasonable.

The Baños and Chillon stocks are also likely each to be homogeneous, for they are widely separated geographically and have distinct habitats and ecological niches (though Chillon is self-incompatible and so may be less homogeneous than Baños). On the assumption of homogeneity within esculentum and the two hirsutum stocks, the Chillon hybrids' centrotypes may be specified by the same sort of reasoning. Their data do not disagree with those of Baños $\left(\chi^{2}=2 \cdot 45^{27}\right.$, see table. This $\chi^{2}$ takes into account the variances of both the Baños and the Chillon estimates of recombination). One is tempted therefore to write the three Chillon chromosomes in the same way. This implies that the same interchange has occurred in both hirsutum stocks and that they are thus similarly related to the esculentum. However, the Ghillon data do agree well with independence and they do not tolerate a quasi-linkage value of the order of the Baños one $\left(\chi_{1}^{2}\right.$ is $7 \cdot 9844$. This takes into account the variance of the Baños estimate only; the Chillon estimate in both cases is taken from the intercross and backcross data combined). It could be argued that the data are not extensive enough to show significance beyond the $\chi^{2}$ of $2 \cdot 45^{27}$ just mentioned-that in fact the discrepancy may be real and is therefore worth considering further. Taken at its face value, then, the Chillon data show no quasi-linkage: the group I chromosomes are then homocentric, that is both $a$ or both $\beta$, and thus

* Strictly, the data indicate merely that the centromere linked to $s p$ attracts the one linked to non- $m s_{2}$ more than it does the one linked to $m s_{2}$ (or vice versa starting with $m s_{2}$ ); this is conceivably possible if three, or even four types of centromere were involved. But the simpler hypothesis seems preferable and is used by the present writer until proved false. 
either the Chillon or the esculentum stock contains only one kind of centromere. Since the Baños hybrids indicate that the esculentum stock does in fact contain two, it is the Chillon stock which contains only one (all $a$ ).

The interesting point here is that an interchange of centromeres has taken place between Baños and esculentum, and that it may not have taken place between Chillon and esculentum. An interchange implies the probability of interchanges of other centromeres also and, more important from the standpoint of appearance and behaviour, of interchange of the genetic material of several chromosomes. This should result in greater similarity between stocks containing interchanged material than those which do not. It is striking that this is precisely the conclusion concerning the Baños and Chillon forms reached by Sawant from other considerations: the crossability, fertility, linkage relations, chiasma frequency and pollen abortion rates within these stocks and the hybrids indicate that "Baños is more closely related to esculentum than is Chillon". It is Sawant's view (private communication) that there has been no crossing between Baños and Chillon nor between these two and esculentum in the recent past. He does, however, believe it to have been possible at some time for Baños and esculentum, the two for which the present data give the strongest case of centromere interchange, for he has postulated it (1956) in support of a theory of semi-lethal complementary factors as a mechanism of isolation between them. It would be interesting to discover at what distant date such interchange can in fact be excluded, since this would give a minimum for the length of time the differing centromeres within each of these stocks have maintained their differences. Perhaps other tomato geneticists can supply evidence for or against the writer's speculation that the crossing took place in Europe in the early days of cultivation of this plant.

\section{PAST AND FUTURE DATA}

The conclusions possible in the light of the affinity hypothesis have been treated in detail because they indicate the kind of information that affinity data can supply. The treatment serves as a pointer both to the type of work that could be informative in future and to the sort of scrutiny to which past data may be subjected.

The design of affinity experiments has been dealt with in some detail elsewhere (Wallace, 1958a), but two points are worth emphasising here:

(i) If the four factors had been segregating simultaneously in each hybrid, the doubts mentioned above could have been avoided and the conclusions about the Chillon and Baños relations made with more certainty. Moreover, the centromere in the doubly marked chromosome (group IV) could have been mapped in relation to these markers. It is interesting to note that the only one in which centromere position 
in relation to markers is already approximately known by a cytogenetic method is chromosome 2 (group I). An appropriate affinity experiment could serve as a test of this method and of the affinity hypothesis.

(ii) Evidence of quasi-linkage is critical evidence that the markers involved are on different chromosomes; it is worth more than independence data for these leave open the possibility of the markers being far apart on the same chromosome.

The situations described in this paper are very similar to those observed in mice for the genes $r u$ (ruby) and je (jerker) (Wallace, I 958b), where all the "linkage" data come from outcrossed material and a " control" is provided by the occurrence of "independence" data from inbred material.

Concerning past data, it is possible that those more conversant with tomato genetics than the present writer may recall records which can be interpreted in a similar manner to those presented here.

Indeed some information of these kinds is already available. Rick and Butler (1956) state that Fogle and Currence (1950) and Butler (I95 I and I952) found evidence of linkage between $j(\mathrm{~V})$ and wt (X), but the trisomic tests by Rick and Barton (1954) prove their independence. The data of Fogle and Currence are stated to have occurred after a cross between "two dissimilar varieties". This suggests that these data concern quasi-linkage rather than linkage and consequently that $\mathrm{V}$ and $\mathrm{X}$ are thereby proved independent.

On receiving a draft of this paper, Professor L. Butler, University of Toronto, has given the writer further information which is used below. His data quoted above were also from outbred material, being from the $F_{1}$ of crosses between Rouge Naine Hative (or its immediate derivatives) and other American varieties. Thus all the "linkage" data is from outbred material and there is strong evidence that different homologues are involved. Rouge Naine Hative was isolated from the main line of development of the American varieties almost long enough to have become a distinct subspecies (nearly 200 years), and Butler found it to be his most homozygous commercial type: it is therefore reasonable to suppose that it has developed centromeres foreign to many other varieties, and it is thus also an obvious choice for future affinity work.

It is interesting to note that in his $195 \mathrm{I}$ report Butler gives an analysis of the segregation of wt with $f, a, l f, j$, not all, however, simultaneously (the latter linked in this order), from which an approximate idea of centromere position in $\mathrm{V}$ may be gained. $w t-j$ and $w t$-lf have the greatest deviations from 50 per cent. (and the very significant $\chi_{1}^{2}$ values of 83.89 and $98 \cdot 9 \mathrm{I}$ ), wt- $f$ less and $w t$ - $a$ none: this is consistent with a centromere close to $l f$ and $j$ (and of course another close to wt in $\mathrm{X}$ ), but further experiment could determine the exact position.

At the Xth International Genetics Congress at Montreal, Butler commented on the $w t-j$ quasi-linkage and made the following further 
comments, which he has conveyed to the writer with permission to quote:

"I. When a new recessive mutant is crossed with a multiple tester stock it often gives cross-over values in the low forties with several independent markers. These 'false' linkages often disappear when the $\mathrm{F}_{2}$ coupling test is used.

2. Crosses between $L$. esculentum and $L$. pimpinellifolium, which are perfectly interfertile, show linkages of 48 and 52 when great numbers are grown in $\mathrm{F}_{2}$ 's."

These observations also support the existence of quasi-linkage and are susceptible of an affinity interpretation; but since the data were not derived in such a way that it could be the only interpretation, a direct experiment is being planned by T. Pickup, using the two latter species.

Indeed it has been the purpose of this paper to make a case for experiment both to test the reality of affinity in the tomato and to provide material from which may be extracted the information it can give on chromosome mapping and species relations.

\section{SUMMARY}

Sawant's data (I958), which concern the segregation of two pairs of independent markers in the hybrids of two species-crosses, are analysed in order to detect quasi-linkage.

Genes $a$ (linkage group V) and $c$ (linkage group IV) are found to recombine with values significantly below 50 per cent.; genes $s p$ (linkage group IV) and $m s_{2}$ (linkage group I) are found to recombine with a value significantly exceeding 50 per cent. in hybrids from one cross and with a value insignificantly exceeding 50 per cent. in hybrids from the other.

The data are considered in the light of an affinity interpretation. While they are not as extensive as is desirable for a conclusive demonstration of affinity, they fit the hypothesis well.

Assuming affinity, and only two types of centromere, the genetic constitution of the chromosomes corresponding to these three linkage groups may be written:

$\begin{array}{ccccc}\text { V } & \text { IV } & \text { I } & \begin{array}{c}\text { Stock from which } \\ \text { chromosomes obtained }\end{array} & \text { Origin of stock } \\ a \beta & c \text { sp } \beta & m s_{2} \alpha & \text { L. esculentum } & \begin{array}{l}\text { San Marzano and } \\ \text { Pearson }\end{array} \\ +\alpha & ++\alpha & +\beta & \text { L. hirsutum } & \begin{array}{l}\text { Baños } \\ \text { Chillon }\end{array}\end{array}$

where $\alpha$ are centromeres of hirsutum ancestry, and $\beta$ are centromeres of esculentum ancestry.

The presence of a centromere of esculentum ancestry in the Baños stock and one of hirsutum ancestry in the esculentum can most simply be explained on the supposition that an interchange of genetical 
material (by crossing) has taken place since differentiation of the centromeres occurred.

Interchange can be expected to result in greater morphological similarity between these two stocks than between the Chillon and esculentum (between which it is possible that no such exchange has occurred). This expected result coincides with the conclusions drawn by Sawant from morphological, physiological and cytogenetical considerations, namely that "Baños is more closely related to $L$. esculentum than is Chillon".

The relations between groups $\mathrm{V}$ and $\mathrm{X}$ are briefly discussed; affinity is found to reconcile the paradox that some data show linkage between them and others independence.

An outline is given of the design of experiments to test the affinity hypothesis.

\section{REFERENCES}

BUTLER, L. 195I. New linkage groups in the tomato. F. Hered., 42 , 100-104. BUTLER, L. 1952. The linkage map of the tomato. F. Hered., 43, 25-35.

CHATtERley, F. J. I958. Ph.D. dissertation. Oxford Univ. Library.

FISHER, R. A., LYON, M. F., AND OWEN, A. R. G. I947. The sex chromosome in the house mouse. Heredity, $I, 355-365$.

FOGLE, H. W., AND CURRENCE, T. M. I950. Inheritance of fruit weight and earliness. in a tomato cross. Genetics, $35,363-380$.

мichie, D. 1955a. Affinity. Proc. Roy. Soc. B, I44, 24 1-259.

MIChIE, D. 1955b. Genetical studies with "vestigial tail" mice. III. New independence data. F. Genetics, 53, 285-294.

Parsons, P. A. 1959. Possible affinity between linkage groups V and XIII of the house mouse. Genetica, 29, 304-3II.

RICK, C. M., AND BARTON, D. W. I954. Cytological and genetical identification of the primary trisomics of the tomato. Genetics, 39, 640-666.

RICK, C. M., AND BUTLER, L. 1956. Cytogenetics of the tomato. Advances in Genetics, $8,267-382$.

SAWANT, A. C. 1956. Semi-lethal complementary factors in a tomato species hybrid. Evolution, ro, 93-96.

SAWANT, A. G. I958. Cytogenetics of interspecific hybrids, Lycopersicon esculentum Mill. and L. hirsutum Humb. and Bonpl. Genetics, 43, 502-515.

WALlAGE, M. E. 1958a. Experimental evidence for a new genetic phenomenon. Phil. Trans. Roy. Soc. B, 24I, 21 I-254.

WALLACE, M. E. I $958 b$. New linkage and independence data for ruby and jerker in the mouse. Heredity, $12,453-462$.

Wallace, м. E. 1960a. Possible cases of affinity in cotton. Heredity, 14, 263-274. WALLACE, M. E. I96o $b$. Affinity : evidence from an outcrossing programme in mice. I. Results from the use of segregating inbred lines. (In press.)

WRIGHT, M. E. ( = WALLACE). 1947. Two sex-linkages in the house mouse with unusual recombination values. Heredity, $1,349-354$. 